\title{
Complementary and Alternative Medicine Practice Among Saudi Patients with Chronic Kidney Disease: A Cross-Sectional Study
}

This article was published in the following Dove Press journal: International Journal of Nephrology and Renovascular Disease

\author{
Layla AlAnizy' \\ Khalid AIMatham ${ }^{2}$ \\ Asmaa Al Basheer ${ }^{3}$ \\ Isamme AlFayyad (D) ${ }^{4}$ \\ 'Department of Pharmacy, King Fahad \\ Medical City, Riyadh, Saudi Arabia; \\ ${ }^{2}$ Department of Internal Medicine, King \\ Fahad Medical City, Riyadh, Saudi Arabia; \\ ${ }^{3}$ College of Pharmacy, Jazan University, \\ Jazan, Saudi Arabia; ${ }^{4}$ Research Center, \\ King Fahad Medical City, Riyadh, Saudi \\ Arabia
}

Objective: Complementary and alternative medicine (CAM) practice in patients with chronic kidney disease (CKD) has significantly increased. However, statistics regarding CAM practices among patients with CKD in Saudi and worldwide are limited. Hence, this study aimed to explore the prevalence and types of CAM in Saudi patients with CKD.

Methods: A cross-sectional study was conducted in 315 patients, who were divided into CKD stages 3-4, CKD stage 5-hemodialysis, and kidney transplant with functioning allografts, by using a convenience sampling technique between September and December 2018. Next, they answered a self-administered questionnaire. The study outcomes were the prevalence of CAM, CAM types, reasons for using herbs, and the source of information about CAM.

Results: Overall, $54.9 \%$ of the study participants were current CAM users, of which $88.4 \%$ were herbal consumers. Patients with CKD stages 3-4 accounted for $87.3 \%$ of the CAM users, followed by those with CKD 5-hemodialysis (7.5\%) and CKD-transplant recipients $(5.2 \%)$. CAM practice was associated with monthly income $(\mathrm{P}=0.021)$. Meanwhile, $79 \%$ of CAM users did not report their CAM practices to their primary physicians. Nigella sativa and parsley were the most commonly consumed herbs by CAM users [94 (61.4\%) and 78 (51\%), respectively].

Conclusion: CAM practice and herb consumption were highly prevalent among patients with CKD. Patients inadequately inform the primary physicians about their CAM practices. Therefore, healthcare providers are encouraged to inquire about these practices.

Keywords: alternative medicine, complementary medicine, chronic kidney disease, Saudi Arabia

\section{Introduction}

Chronic kidney disease (CKD) is a major universal public health problem due to its increasing incidence and high prevalence and its associated adverse complications, such as end-stage renal disease (ESRD), cardiovascular disease, and premature death. ${ }^{1-3}$ Patients with CKD need daily care and multiple conventional pharmacologic treatments. However, despite the advances of contemporary medicine, complementary and alternative medicine (CAM) still prevails, even in the developed societies. ${ }^{4-7}$ CAM is defined as "a group of diverse medical and healthcare systems, practices, and products that are not generally considered to be a part of conventional medicine". 8 The prevalence of CAM usage varies worldwide, accounting for $10-40 \%$ in different European countries, $40-60 \%$ in the USA, $49 \%$ in Australia, $75 \%$ in Africa, and up to $21.6-90 \%$ in Saudi Arabia. ${ }^{4-7,9-11}$
Correspondence: Layla AlAnizy Department of Pharmacy, King Fahad Medical City, PO Box 59046, Riyadh I I525, Saudi Arabia

Tel +966-I I 288999

Email lalanizy@kfmc.med.sa 
Considering the sequelae of kidney failure and the possible adverse impact on the quality of life, ${ }^{12-14}$ many patients shift to CAM practices to cope with the symptoms and control the disease. However, statistics regarding CAM practices among patients with CKD in Saudi Arabia and worldwide are limited, possibly because many patients who practice CAM for CKD may withhold this information from their primary healthcare providers. ${ }^{15}$ In Saudi Arabia, the prevalence of CAM is influenced by traditional habits and religious beliefs. Supplication and recitation from the Holy Quran, drinking Zamzam water (water from the holy city of Mecca), cupping (Alhijamah), and drinking camel milk, camel urine, and honey are common CAM practices in Saudi communities. ${ }^{9,10}$

The idea that CAM practices are safe is a widely believed fallacy. ${ }^{16,17}$ In fact, small quantities of CAM ingredients can lead to adverse effects, such as hypertension, dermatitis, anaphylaxis, and nephrotoxicity induction. ${ }^{18,19}$ Furthermore, several herbs used by renal allograft recipients can interfere with the metabolism of immunosuppressive medications. ${ }^{18,19}$

Several studies have investigated the prevalence of CAM use among patients with CKD and renal transplant recipients. ${ }^{18-23}$ Osman et al showed that $52 \%$ of patients with CKD were using CAM, of whom $78 \%$ were using herbal and natural products. Another study revealed that $64.4 \%$ of hemodialysis patients used at least one CAM type. ${ }^{19}$

Data regarding CAM practice among patients with CKD at different stages of their disease (ESRD, dialysis, and transplantation) that are included in the Saudi population are insufficient. Hence, this study aims to determine the prevalence and types of CAM usage in Saudi patients with CKD.

\section{Materials and Methods Study Design and Setting}

A cross-sectional study was conducted among patients with CKD between September and December 2018 at the outpatient nephrology clinics in our tertiary care hospital.

\section{Study Population}

We included patients with CKD who were older than 18 years, willing to participate in the study, and diagnosed with any of the following for at least 6 months: CKD stages 3-4, CKD stage 5-hemodialysis, or CKD-transplant recipients with functioning allografts. Patients who had mental or psychological limitations that were incapable to respond to the survey or manage their self-medication were excluded.
We used convenient sampling technique for patient recruitment. Furthermore, a trained study coordinator distributed a self-administered questionnaire to those patients who met the inclusion criteria and interviewed the illiterate patients.

\section{Data Collection Instrument and Procedure}

To collect data, we used a self-administered questionnaire. The questionnaire was adopted from Osman et al with official permission. ${ }^{19}$ It consisted of two parts. The first part captured the demographics (age, sex, marital status, educational level, current job, place of living, and family monthly income) and clinical characteristics (CKD stages) of the participants. The second part included questions that assessed the prevalence of CAM, CAM types (herbals, honey, cupping [Alhijamah], massage, and others), reasons for using herbs, how patients acquired information about $\mathrm{CAM}$, and the practice of reporting CAM use to physicians.

\section{Sample Size Calculation}

Cochran's method was used for estimating the sample size with $95 \%$ confidence interval, and $50 \%$ was assumed to be the prevalence rate of CAM use in patients with CKD and a population of $1000 \mathrm{CKD}$ and kidney transplant recipients (cases on active treatment and follow-up at the outpatient nephrology clinics in 2017). As calculated, a minimum of 278 participants were required for this study.

\section{Statistical Analysis}

All statistical analyses were performed using the Statistical Software Package for the Social Sciences version 24 for Windows (Chicago, IL). For descriptive statistics, we computed the means, standard deviations (SD), frequencies, and percentages. Pearson chi-square test, Fisher's exact test, and independent-sample $t$-test were used for the comparative analysis (stratification of CAM users and nonusers and of herbal users and nonusers). Moreover, $\mathrm{P}<0.05$ was considered significant.

\section{Ethical Considerations}

This study was approved by the institutional review board (IRB) of King Fahad Medical City (IRB log: 17-454). Patients' completion of the questionnaire implied their consent to participate in the study, and the IRB approved the process of implied consent. The identity of the study participants remained anonymous. 


\section{Results}

\section{Demographic Characteristics and CAM Practice}

A total of 390 questionnaires were distributed in an attempt to reach the final sample size of 278. Finally, 315 patients have completed the questionnaire and included in the final data analysis, with a response rate of $80.1 \%$. Out of these patients, $173(54.9 \%)$ were CAM users, with a mean age of $37.65 \pm 16.78$ years compared with $36.61 \pm 16.31$ for CAM nonusers $(n=142)$. From the 315 patients, 274 were at CKD stages 3-4, 19 were at CKD stage 5-hemodialysis, and 22 were CKD-transplant recipients. Approximately 151 (87.3\%) of CAM users were patients with CKD stages 3-4, followed by those with CKD stage 5-hemodialysis [13 (7.5\%)] and CKDtransplant recipients $[9(5.2 \%)]$ (Table 1).
Monthly income and CAM practice had a statistically significant difference $(P=0.021)$. Post hoc analysis revealed that monthly income [5001-10,000 Saudi Arabian Riyals (SAR)] is significantly associated ( $\mathrm{P}=$ 0.008 ) with CAM practice (reference category was the monthly income of $>10,000 \mathrm{SR}$ ). The stratification of CAM users and nonusers with their characteristics is summarized in Table 1.

\section{Demographic Characteristics and Herbal Practice}

A total of 153 (88.4\%) CAM patients were herbal users, with a mean age of $37.24 \pm 16.66$ years. Of these 153 CAM patients, 135 (88.2\%) were at CKD stages 3-4, 9 (5.9\%) were at $\mathrm{CKD}$ stage 5-hemodialysis, and 9 (5.9\%) were CKD-transplant recipients. Most of the herbal users were

Table I Comparative Analysis by Stratification of CAM Users and Nonusers with Their Characteristics

\begin{tabular}{|c|c|c|c|c|c|c|}
\hline & \multicolumn{4}{|c|}{ CAM Users, n (\%) } & \multirow[t]{2}{*}{ Nonusers, n (\%) } & \multirow[t]{2}{*}{$P$ value } \\
\hline & All & CKD Stages 3-4 & CKD Stage 5-HD & CKD-Transplant & & \\
\hline Numbers & $173(54.9)$ & I5I (87.3) & $13(7.5)$ & $9(5.2)$ & $142(45.1)$ & - \\
\hline Age in years (mean \pm SD) & $37.65 \pm 16.78$ & $36.63 \pm 15.70$ & $50.54 \pm 24.50$ & $40.67 \pm 14.76$ & $36.61 \pm 16.31$ & 0.577 \\
\hline $\begin{array}{l}\text { Gender } \\
\text { Male } \\
\text { Female }\end{array}$ & $\begin{array}{l}69(39.9) \\
104(60.1)\end{array}$ & $\begin{array}{l}58(38.4) \\
93(6 I .5)\end{array}$ & $\begin{array}{l}5(38.4) \\
8(6 I .5)\end{array}$ & $\begin{array}{l}6(66.6) \\
3(33.3)\end{array}$ & $\begin{array}{l}51(35.9) \\
91(64.1)\end{array}$ & 0.470 \\
\hline $\begin{array}{l}\text { Marital status } \\
\text { Single } \\
\text { Married } \\
\text { Divorced }\end{array}$ & $\begin{array}{l}44(25.4) \\
119(68.8) \\
10(5.8)\end{array}$ & $\begin{array}{l}40(26.5) \\
104(68.9) \\
7(4.6)\end{array}$ & $\begin{array}{l}3(23.1) \\
7(53.8) \\
3(23.1)\end{array}$ & $\begin{array}{l}1(11.1) \\
8(89.9) \\
0\end{array}$ & $\begin{array}{l}50(35.5) \\
85(60.3) \\
6(4.2)\end{array}$ & 0.147 \\
\hline $\begin{array}{l}\text { Education } \\
\text { Illiterate } \\
\text { Primary } \\
\text { Secondary } \\
\text { University }\end{array}$ & $\begin{array}{l}8(4.6) \\
21(12.1) \\
62(35.8) \\
82(47.4)\end{array}$ & $\begin{array}{l}7(4.6) \\
14(9.2) \\
55(36.42) \\
75(49.6)\end{array}$ & $\begin{array}{l}1(7.6) \\
6(46.2) \\
3(23.1) \\
3(23.1)\end{array}$ & $\begin{array}{l}0 \\
\text { I (II) } \\
4(44.5) \\
4(44.5)\end{array}$ & $\begin{array}{l}8(5.6) \\
9(6.4) \\
62(43.7) \\
63(44.3)\end{array}$ & 0.233 \\
\hline $\begin{array}{l}\text { Occupation } \\
\text { Employed } \\
\text { Unemployed }\end{array}$ & $\begin{array}{l}37(21.4) \\
48(78.6)\end{array}$ & $\begin{array}{l}31(42.5) \\
42(57.5)\end{array}$ & $\begin{array}{l}4(44.4) \\
5(55.6)\end{array}$ & $\begin{array}{l}2(66.7) \\
\text { I (33.3) }\end{array}$ & $\begin{array}{l}28(40) \\
42(60)\end{array}$ & 0.658 \\
\hline $\begin{array}{l}\text { Location } \\
\text { Riyadh } \\
\text { Outside Riyadh }\end{array}$ & $\begin{array}{l}109(63) \\
64(37)\end{array}$ & $\begin{array}{l}95(62.9) \\
56(37.1)\end{array}$ & $\begin{array}{l}9(69.2) \\
4(30.8)\end{array}$ & $\begin{array}{l}5(55.6) \\
4(44.4)\end{array}$ & $\begin{array}{l}75(54.3) \\
63(45.7)\end{array}$ & 0.123 \\
\hline $\begin{array}{l}\text { Monthly income (SAR) } \\
\quad \leq 5000 \\
5001-10,000 \\
\geq 10,000\end{array}$ & $\begin{array}{l}40(60.6) \\
19(28.8) \\
7(10.7)\end{array}$ & $\begin{array}{l}33(57.9) \\
15(26.3) \\
9(15.8)\end{array}$ & $\begin{array}{l}3(42.9) \\
3(42.9) \\
I(14.2)\end{array}$ & $\begin{array}{l}\text { I (33.3) } \\
\text { I (33.3) } \\
\text { I (33.3) }\end{array}$ & $\begin{array}{l}35(56.6) \\
6(17) \\
13(26.6)\end{array}$ & $0.02 I^{*}$ \\
\hline
\end{tabular}

Note: *Significant at $\mathrm{P}<0.05$.

Abbreviations: SAR, Saudi Arabian Riyal; CKD, chronic kidney disease; HD, hemodialysis. 
females [94 (61.4\%)], married [106 (69.3\%)], at the university level [74 (49\%)], unemployed [119 (77.8\%)], living outside Riyadh [60 (39.2\%)], and had a monthly income of $\leq 5000$ [31 (53.4\%)]. No statistically significant difference was found between the characteristics of herbal users and nonusers. The stratification of herbal users and nonusers with their characteristics is summarized in Table 2.

\section{Types of Herbs and Reasons for Usage}

The most frequently reported herbs used by herbal users were Nigella sativa [94 (61.4\%)], followed by parsley [78 (51\%)], lemon [60 (39.2\%)], and garlic [56 (36.6\%)]. In patients with CKD stages 3-4, the most frequently used herbs were N. sativa $[79(58.5 \%)]$ and parsley $[72(53.3 \%)]$; the least used ones were barley [18 (13.3\%)] and hibiscus [20 (14.8\%)]. Moreover, the top most reported herb in patients with CKD stage 5-hemodialysis was the $N$. sativa [9 (100\%)].
Meanwhile, lemon was the most used herb reported by CKDtransplant recipients [6 (66.7\%)]. Furthermore, $62 \%$ of our study participants used herbs for treating CKD or other comorbidities, 30.1\% for prophylaxis from other diseases, and 15.0\% for improving their condition without harm (Table 3).

Remarkably, 250 (79.4\%) of the study participants did not report CAM practice to their primary physicians, and $36.5 \%$ of them were assessed by their primary physicians about CAM practice. Friends/family [81 (52.9\%)] was the most reported source of information about herbal use, followed by media [52 $(33.9 \%)]$, healthcare provider [17 (11.1\%)], and herbalists [3 (2\%)]. Of the 49 responses about the source of buying herbs, approximately 35 (71\%) herbal users purchased their herbs from herbal stores, whereas 13 (26.5\%) bought their herbs from a supplement store. Finally, $38.2 \%$ and $14.5 \%$ of CAM users have reported the use of honey and Alhijamah, respectively.

Table 2 Comparative Analysis by Stratification of Herbal Users and Nonusers with Their Characteristics

\begin{tabular}{|c|c|c|c|c|c|c|}
\hline & \multicolumn{4}{|c|}{ Herbal Users, n (\%) } & \multirow[t]{2}{*}{ Nonusers, n (\%) } & \multirow[t]{2}{*}{$P$ value } \\
\hline & All & CKD Stages 3-4 & CKD Stage 5-HD & CKD-Transplant & & \\
\hline Number & $153(48.6)$ & I35 (88.2) & $9(5.9)$ & $9(5.9)$ & $162(51.4)$ & - \\
\hline Age & $37.24 \pm 16.66$ & $35.94 \pm 15.56$ & $53.22 \pm 25.97$ & $40.66 \pm 14.76$ & $37.18 \pm 16.49$ & 0.950 \\
\hline $\begin{array}{l}\text { Gender } \\
\text { Male } \\
\text { Female }\end{array}$ & $\begin{array}{l}59(38.6) \\
94(61.4)\end{array}$ & $\begin{array}{l}50(37) \\
85(62.2)\end{array}$ & $\begin{array}{l}3(33.3) \\
6(66.6)\end{array}$ & $\begin{array}{l}6(66.6) \\
3(33.3)\end{array}$ & $\begin{array}{l}61(37.7) \\
101(62.3)\end{array}$ & 0.868 \\
\hline $\begin{array}{l}\text { Marital Status } \\
\text { Single } \\
\text { Married } \\
\text { Divorced }\end{array}$ & $\begin{array}{l}39(25.5) \\
106(69.3) \\
8(5.2)\end{array}$ & $\begin{array}{l}36(26.7) \\
93(68.9) \\
6(4.4)\end{array}$ & $\begin{array}{l}2(22.25) \\
5(55.5) \\
2(22.2)\end{array}$ & $\begin{array}{l}I(I I . I) \\
8(88.8) \\
0\end{array}$ & $\begin{array}{l}55(34.2) \\
98(60.8) \\
8(5)\end{array}$ & 0.242 \\
\hline $\begin{array}{l}\text { Education } \\
\text { Illiterate } \\
\text { Primary } \\
\text { Secondary } \\
\text { University }\end{array}$ & $\begin{array}{l}7(12.1) \\
18(34.2) \\
54(4.7) \\
74(49)\end{array}$ & $\begin{array}{l}6(4.4) \\
13(9.6) \\
48(35.5) \\
68(50.3)\end{array}$ & $\begin{array}{l}\text { I }(\text { I I.I) } \\
4(44.4) \\
2(22.2) \\
2(22.2)\end{array}$ & $\begin{array}{l}0 \\
I(I I . I) \\
4(44.4) \\
4(44.4)\end{array}$ & $\begin{array}{l}9(5.6) \\
12(7.4) \\
70(43.2) \\
71(43.8)\end{array}$ & 0.345 \\
\hline $\begin{array}{l}\text { Occupation } \\
\text { Employed } \\
\text { Unemployed }\end{array}$ & $\begin{array}{l}34(22.8) \\
119(77.8)\end{array}$ & $\begin{array}{l}29(43.9) \\
37(56.1)\end{array}$ & $\begin{array}{l}3(50) \\
3(50)\end{array}$ & $\begin{array}{l}2(66.7) \\
I(33.3)\end{array}$ & $\begin{array}{l}3 \mid(19.1) \\
|3|(80.9)\end{array}$ & 0.498 \\
\hline $\begin{array}{l}\text { Location } \\
\text { Riyadh } \\
\text { Outside Riyadh }\end{array}$ & $\begin{array}{l}93(60.8) \\
60(39.2)\end{array}$ & $\begin{array}{l}83(61.4) \\
52(38.5)\end{array}$ & $\begin{array}{l}5(55.55) \\
4(44.4)\end{array}$ & $\begin{array}{l}5(55.5) \\
4(44.4)\end{array}$ & $\begin{array}{l}91(56.2) \\
71(43.8)\end{array}$ & 0.407 \\
\hline $\begin{array}{l}\text { Monthly income (SAR) } \\
\leq 5000 \\
5,001-10,000 \\
\geq 10,001\end{array}$ & $\begin{array}{l}31(53.4) \\
17(29.3) \\
10(17.2)\end{array}$ & $\begin{array}{l}29(56.9) \\
14(27.5) \\
8(15.6)\end{array}$ & $\begin{array}{l}\text { I (25) } \\
2(50) \\
\text { I (25) }\end{array}$ & $\begin{array}{l}\text { I (33.3) } \\
\text { I (33.3) } \\
\text { I (33.3) }\end{array}$ & $\begin{array}{l}36(58.1) \\
11(17.7) \\
15(24.2)\end{array}$ & 0.283 \\
\hline
\end{tabular}

Abbreviations: SAR, Saudi Arabian Riyal; CKD, chronic kidney disease; HD, hemodialysis. 
Table 3 Most Frequently Reported Herbs Used by Herbal User Participants, n (\%)

\begin{tabular}{|c|c|c|c|c|}
\hline Herbs & $\begin{array}{l}\text { All Users } \\
(n=153)\end{array}$ & $\begin{array}{l}\text { CKD Stages 3-4 } \\
(n=135)\end{array}$ & $\begin{array}{l}\text { CKD Stage 5-HD } \\
(n=9)\end{array}$ & $\begin{array}{l}\text { CKD-Transplant } \\
(n=9)\end{array}$ \\
\hline Parsley & $78(5 I)$ & $72(53.3)$ & $3(33.3)$ & $3(33.3)$ \\
\hline Barley & $23(15)$ & $18(13.3)$ & $3(33.3)$ & $2(22.2)$ \\
\hline Aniseed & $42(27.5)$ & $37(27.4)$ & $3(33.3)$ & $2(22.2)$ \\
\hline Commiphora myrrha & $30(19.6)$ & $25(18.5)$ & $3(33.3)$ & $2(22.2)$ \\
\hline Garlic & $56(36.6)$ & $49(36.3)$ & $2(33.3)$ & $5(55.6)$ \\
\hline Lemon & $60(39.2)$ & 51 (37.8) & $3(33.3)$ & $6(66.7)$ \\
\hline Nigella sativa & $94(61.4)$ & $79(58.5)$ & $9(100)$ & $6(4.4)$ \\
\hline Fenugreek & $35(22.9)$ & $31(23)$ & $3(33.3)$ & $I(I I . I)$ \\
\hline Olive oil & $39(25.5)$ & $33(24.4)$ & $3(33.3)$ & $3(33.3)$ \\
\hline Thyme & $32(20.9)$ & $29(21.5)$ & $2(22.3)$ & I (II.I) \\
\hline Hibiscus & $21(13.7)$ & $20(14.8)$ & 0 & I (II.I) \\
\hline Gum Arabic & $39(25.5)$ & $34(2 \mid .2)$ & $2(22.2)$ & $3(33.3)$ \\
\hline \multicolumn{5}{|l|}{ Most common reasons for herbal usage } \\
\hline Treatment of CKD or other comorbidities $(n=96)$ & $96(62.7)$ & $82(60.7)$ & $9(100)$ & $5(55.6)$ \\
\hline Prophylaxis from disease $(n=46)$ & $46(30.1)$ & $4 \mathrm{I}(30.4)$ & $\mathrm{I}(\mathrm{II} . \mathrm{I})$ & $4(44.4)$ \\
\hline Belief that herbs may improve condition without harm $(n=23)$ & $23(15)$ & $19(14.1)$ & $2(22.2)$ & $2(22.2)$ \\
\hline
\end{tabular}

Abbreviations: CKD, chronic kidney disease; HD, hemodialysis.

\section{Discussion}

This cross-sectional study reports the practice of CAM in Saudi patients with CKD and renal allograft recipients in a tertiary medical hospital in Riyadh Capital, Saudi Arabia. The practice of CAM has been reported among patients with CKD in the literature internationally; however, our study is the first to assess CAM practice among a sample of Saudi patients with CKD and renal allograft recipients.

Our study revealed a high prevalence of CAM practice in Saudi patients with CKD and renal allograft recipients. Many of the study patients who revealed the practice of certain CAM therapy types had reported herbal use as the most common CAM therapy in their health self-management practice.

Regular CAM practice was reported by $54.9 \%$ of our study participants. These findings are similar to previously reported figures among patients with CKD. ${ }^{20-26}$ In our study, the practice of CAM was observed in $7.5 \%$ of patients with CKD stage 5-hemodialysis and 5.2\% in CKD-transplant recipients. Interestingly, Osman et al reported higher percentages of CAM practice among hemodialysis patients (33\%) and transplant recipients (40.5\%) in Egypt. ${ }^{19}$ In addition, Sa'ed et al reported a higher prevalence $(64.4 \%)$ of CAM practice among dialysis patients in Palestine. ${ }^{24}$ Other studies have also shown an increased prevalence of CAM practice among dialysis and transplant recipients. ${ }^{18,20,21,25}$ However, Hess et al had reported a similar prevalence of CAM practice among CKD-transplant recipients in Switzerland. ${ }^{27}$ The nature of the renal disease, which can exacerbate toxicity by some ingredients because of the loss of the excretory function of the kidneys, might contribute to the low prevalence of CAM practice in patients with CKD stage 5-hemodialysis and CKD-transplant recipients in our study. ${ }^{24,27}$

In the present study, we stratified the usage of CAM and herbal use with the study participants' characteristics. Contrary to previous literature that reported a significant influence of patients' demographic characteristics and CAM practice among patients with $\mathrm{CKD},{ }^{18-23,25}$ our figures showed that monthly income was the only characteristic that had a significant association $(\mathrm{P}=0.021)$ with CAM practice, whereas age, gender, educational status, marital status, occupational status, and geographic region had no influence on CAM practice. The difference in the results between various studies about CAM practice may be related to the differences in the study sample, the geographical setting of these studies, or the fact that patients were reluctant to report their CAM practice to healthcare providers. ${ }^{20}$ Most especially, patients with CKD stage 5-hemodialysis and CKD-transplant recipients may not disclose their CAM practice, considering their critical status and also to avoid blaming them by their physicians. However, the practice of CAM among transplant recipients requires exceptional supervision and follow-up because they are considered as distinctive patients. 
Approximately $96(62.7 \%)$ of the study participants were using CAM for treating CKD or other comorbidities. These results are similar to previous studies that reported a high prevalence (52-72\%) of CAM use in patients with chronic diseases, including CKD. ${ }^{19,28,29}$

The present study revealed that $79.4 \%$ of CAM users did not report CAM practice to their primary physicians. This practice continued without informing healthcare providers, as shown in our study and other studies, ${ }^{19,30,31}$ primarily because healthcare providers did not inquire on CAM practice. Therefore, healthcare providers must be aware of CAM practice among their patients and critically inquire about such practices that may interact with the conventional treatment. ${ }^{32,33}$ They must also offer the appropriate evidence about the benefits or risks of using CAM. Furthermore, healthcare providers must differentiate between harmless CAM (prayer) and harmful CAM (herbal therapy), with anticipated toxicity and advice based on scientific merits and practice of herbal therapies for patients with CKD. ${ }^{24}$

In the current study, the most commonly used CAM type was herbs $(88.4 \%)$, followed by honey (38.2\%) and Alhijamah (14.5\%). These results are consistent with the data reported by Alrowis et al wherein they revealed different CAM modalities in the Saudi population. ${ }^{9}$ The herbal use was $8 \%-76 \%$, honey was $14 \%-73 \%$, and dietary products were $6 \%-82 \%$. Alhijamah and acupuncture were the least practiced type. Another study involving patients with CKD revealed a high prevalence of herbal and natural product practice (78\%), followed by mind and body procedures $(21.6 \%) .{ }^{19}$

Most of the herbs used by the study participants were obtained from herbal and supplement stores. Over a half of the study participants received CAM therapy that was guided by friends/family and one-third by media. The absence of legislation to regulate CAM practice in Saudi Arabia may lead to improper practice in health-seeking behaviors, such as purchasing of CAM products and needing for nonmedical guiding advice. Therefore, unsurprisingly, many of the CAM users abandoned their practice from their nephrologist, as reported in the present study and other similar studies, because physicians and other healthcare providers did not inquire about CAM practice. ${ }^{19,30}$ Thus, nephrologists and other healthcare providers should explicitly ask their patients about herbal practices that may interact with the patients' medications and affect their compliance to the conservative medical therapy and may probably be harmful and detrimental in the care plan. ${ }^{26,30}$
Although certain traditional therapies could have scientific merits and evidence supporting its use, some traditional therapies have no such evidence and might be potentially harmful to the patients. ${ }^{1,34}$ The common types of herbs used among CAM users in the present study were N. sativa [94, $(61.43 \%)]$, followed by parsley [78 (51\%)]. However, $N$. sativa constitutes the topmost reported herb in CKD stages 3-4 and CKD stage 5-hemodialysis. These findings conform to other studies results reported from the Arab world. ${ }^{19,24}$ $N$ sativa is part of the prophetic medicine that is common in the Arabic countries, ${ }^{35}$ but no sufficient reliable evidence can support its use among patients with CKD apart from the possibility of having an antioxidant impact. ${ }^{36}$

Meanwhile, this study has some limitations. For instance, its cross-sectional design and the results are subjected to recall bias regarding CAM practice. Moreover, the convenience sampling method (nonrandom) is considered as a source of bias because it will produce a non-representative sample.

\section{Conclusion}

The present study provides information on the different CAM types practiced by a representative sample of Saudi patients with CKD. Given the high prevalence of CAM practice, which is generally not disclosed, nephrologists, clinical pharmacists, and other healthcare providers need to inquire about their patients' CAM practice and educate them according to an evidence-based practice. Experimental research is encouraged to investigate the consumption and toxicity levels of herbs to provide an additional understanding of the chemical ingredients and pharmacological impact of these therapies.

\section{Ethics Approval and Consent to Participate}

The institutional review board approval was obtained from King Fahad Medical City (IRB log: 17-454). Patients' completion of the questionnaire implied their consents to take part in the study. The identity of the participants was kept anonymous. The IRB approved the process of implied consent.

\section{Abbreviations}

CAM, complementary and alternative medicine; CKD, chronic kidney disease; ESRD, end-stage renal disease; IRB, institutional review board; KFMC, King Fahad Medical City.

\section{Data Sharing Statement}

All data generated or analyzed during this study are included in this published article. 


\section{Acknowledgments}

We want to extend our appreciation to Ms. Nouf Al-Anizy, Mudi AlShaib, and Huda Abdullah from the nursing department at KFMC for their efforts in data collections, and to Ms. Yara Beshawri from the research center at KFMC for her statistical consultation.

\section{Funding}

This study was supported by grants from the research center at King Fahd Medical City. The funding body had no influence study design; data collection, data analysis, data interpretation, and in writing the manuscript.

\section{Disclosure}

The authors report no conflicts of interest in this work.

\section{References}

1. Jha V, Garcia-Garcia G, Iseki K, et al. Chronic kidney disease: global dimension and perspectives. Lancet. 2013;382:260-272. doi:10.1016/ S0140-6736(13)60687-X

2. Levey AS, Eckardt KU, Tsukamoto Y, et al. Definition and classification of chronic kidney disease: a position statement from Kidney Disease: improving Global Outcomes (KDIGO). Kidney Int. 2005;67:2089-2100. doi:10.1111/j.1523-1755.2005.00365.x

3. Go AS, Chertow GM, Fan D, McCulloch CE, Hsu CY. Chronic kidney disease and the risks of death, cardiovascular events, and hospitalization. $N$ Engl J Med. 2004;351:1296-1305. doi:10.1056/ NEJMoa041031

4. Clarke TC, Black LI, Stussman BJ, Barnes PM, Nahin RL. Trends in the use of complementary health approaches among adults: united States, 2002-2012. Natl Health Stat Report. 2015;79:1-16.

5. Posadzki P, Watson LK, Alotaibi A, Ernst E. Prevalence of use of complementary and alternative medicine (CAM) by patients/consumers in the UK: systematic review of surveys. Clin Med (Northfield Il). 2013;13(2):126-131. doi:10.7861/clinmedicine.13-2-126

6. Joos S, Musselmann B, Szecsenyi J. Integration of complementary and alternative medicine into family practices in Germany: results of a national survey. Evid Based Complement Altern Med. 2011;2011:1-8. doi:10.1093/ecam/nep019

7. Molassiotis A, Fernandez-Ortega P, Pud D, et al. Use of complementary and alternative medicine in cancer patients: a European survey. Ann Oncol. 2005;16:655-663. doi:10.1093/annonc/mdi110

8. Pearson NJ, Chesney MA. The national center for complementary and alternative medicine. Acad Med. 2007;82:967. doi:10.1097/ ACM.0b013e31814a5462

9. Alrowais NA, Alyousefi NA. The prevalence extent of Complementary and Alternative Medicine (CAM) use among Saudis. Saudi Pharm J. 2017;25:306-318. doi:10.1016/j.jsps.2016.09.009

10. AlBedah AM, Khalil MK, Elolemy AT, et al. The use of and out-ofpocket spending on complementary and alternative medicine in Qassim province, Saudi Arabia. Ann Saudi Med. 2013;33:282-289. doi:10.5144/0256-4947.2013.282

11. Sait KH, Anfinan NM, Eldeek B, et al. Perception of patients with cancer towards support management services and use of complementary alternative medicine-a single institution hospital-based study in Saudi Arabia. Asian Pac J Cancer Prev. 2014;15:2547-2554. doi:10.7314/APJCP.2014.15.6.2547
12. Gorodetskaya I, Zenios S, Mcculloch CE, et al. Health-related quality of life and estimates of utility in chronic kidney disease. Kidney Int. 2005;68:2801-2808. doi:10.1111/j.1523-1755.2005.00752.x

13. Perlman RL, Finkelstein FO, Liu L, et al. Quality of life in chronic kidney disease (CKD): a cross-sectional analysis in the Renal Research Institute-CKD study. Am J Kidney Dis. 2005;45:658-666. doi:10.1053/j.ajkd.2004.12.021

14. Mujais SK, Story K, Brouillette J, et al. Health-related quality of life in CKD patients: correlates and evolution over time. Clin J Am Soc Nephrol. 2009;4:1293-1301. doi:10.2215/CJN.05541008

15. Markell MS. Potential benefits of complementary medicine modalities in patients with chronic kidney disease. Adv Chronic Kidney Dis. 2005;12:292-299. doi:10.1016/j.ackd.2005.03.004

16. Teschke R, Frenzel C, Glass X, Schulze J, Eickhoff A. Herbal hepatotoxicity: a critical review. Br J Clin Pharmacol. 2013;75:630-636. doi:10.1111/j.1365-2125.2012.04395.x

17. Huxtable RJ. The myth of beneficent nature: the risks of herbal preparations. Ann Intern Med. 1992;117:165-166. doi:10.7326/ 0003-4819-117-2-165

18. Nowack R, Ballé C, Birnkammer F, Koch W, Sessler R, Birck R. Complementary and alternative medications consumed by renal patients in southern Germany. J Ren Nutr. 2009;19:211-219. doi:10.1053/j.jrn.2008.08.008

19. Osman NA, Hassanein SM, Leil MM, NasrAllah MM. Complementary and alternative medicine use among patients with chronic kidney disease and kidney transplant recipients. J Ren Nutr. 2015;25:466-471. doi:10.1053/j.jrn.2015.04.009

20. Rao AS, Phaneendra D, Pavani CD, et al. Usage of complementary and alternative medicine among patients with chronic kidney disease on maintenance hemodialysis. J Pharm Bioallied Sci. 2016;8:52. doi:10.4103/0975-7406.171692

21. Birdee GS, Phillips RS, Brown RS. Use of complementary and alternative medicine among patients with end-stage renal disease. Evid Based Complement Altern Med. 2013;2013:1-6. doi:10.1155/2013/654109

22. Duncan HJ, Pittman S, Govil A, et al. Alternative medicine use in dialysis patients: potential for good and bad! Nephron Clin Pract. 2007;105:c108-c113. doi:10.1159/000097986

23. Kara B. Herbal product use in a sample of Turkish patients undergoing haemodialysis. J Clin Nurs. 2009;18:2197-2205. doi:10.1111/ jen.2009.18.issue-15

24. Zyoud SH, Al-Jabi SW, Sweileh WM, et al. Use of complementary and alternative medicines in haemodialysis patients: a cross-sectional study from Palestine. BMC Complement Altern Med. 2016;16:204. doi:10.1186/s12906-016-1196-8

25. Akyol AD, Yildirim Y, Toker E, Yavuz B. The use of complementary and alternative medicine among chronic renal failure patients. J Clin Nurs. 2011;20:1035-1043. doi:10.1111/j.13652702.2010.03498.x

26. Castelino L, Nayak-Rao S, Shenoy M. Prevalence of use of complementary and alternative medicine in chronic kidney disease: a cross-sectional single-center study from South India. Saudi J Kidney Dis Transpl. 2019;30(1):185-193. doi:10.4103/1319-2442.252909

27. Hess S, De Geest S, Halter K, Dickenmann M, Denhaerynck K. Prevalence and correlates of selected alternative and complementary medicine in adult renal transplant patients. Clin Transplant. 2009;23:56-62. doi:10.1111/ctr.2009.23.issue-1

28. Saydah SH, Eberhardt MS. Use of complementary and alternative medicine among adults with chronic diseases: United States 2002. J Altern Complement Med. 2006;12:805-812. doi:10.1089/acm.2006.12.805

29. Jouad H, Haloui M, Rhiouani H, El Hilaly J, Eddouks M. Ethnobotanical survey of medicinal plants used for the treatment of diabetes, cardiac and renal diseases in the North centre region of Morocco (Fez-Boulemane). J Ethnopharmacol. 2001;77:175-182. doi:10.1016/S0378-8741(01)00289-6

30. Grant KL. Patient education and herbal dietary supplements. Am J Health Syst Pharm. 2000;57:1997-2003. doi:10.1093/ajhp/57.21.1997 
31. Tangkiatkumjai M, Boardman H, Praditpornsilpa K, Walker DM. Prevalence of herbal and dietary supplement usage in Thai outpatients with chronic kidney disease: a cross-sectional survey. $B M C$ Complement Altern Med. 2013;13:153. doi:10.1186/1472-6882-13-153

32. Koithan M. Let's talk about complementary and alternative therapies. $J$ Nurse Pract. 2009;5:214. doi:10.1016/j.nurpra.2008.12.011

33. Schofield P, Diggens J, Charleson C, Marigliani R, Jefford M. Effectively discussing complementary and alternative medicine in a conventional oncology setting: communication recommendations for clinicians. Patient Educ Couns. 2010;79:143-151. doi:10.1016/j.pec.2009.07.038
34. Dahl N. Herbs and supplements in dialysis patients: panacea or poison. Semin Dial. 2001;14:186-192. doi:10.1046/j.1525-139X.2001. 00051.x

35. Ijaz H, Tulain UR, Qureshi J, et al. Nigella sativa (prophetic medicine): a review. Pak J Pharm Sci. 2017;30:229-234.

36. Ragheb A, Attia A, Eldin WS, Elbarbry F, Gazarin S, Shoker A. The protective effect of thymoquinone, an anti-oxidant and anti-inflammatory agent, against renal injury: a review. Saudi J Kidney Dis Transpl. 2009;20:741-752.

\section{Publish your work in this journal}

The International Journal of Nephrology and Renovascular Disease is an international, peer-reviewed open-access journal focusing on the pathophysiology of the kidney and vascular supply. Epidemiology, screening, diagnosis, and treatment interventions are covered as well as basic

Submit your manuscript here: https://www.dovepress.com/international-journal-of-nephrology-and-renovascular-disease-journal science, biochemical and immunological studies. The manuscript management system is completely online and includes a very quick and fair peer-review system, which is all easy to use. Visit http://www.dovepress.com/testimonials.php to read real quotes from published authors. 